\title{
Möbius Syndrome: Misoprostol Use and Speech and Language Characteristics
}

\author{
Zelita Caldeira Ferreira Guedes ${ }^{1}$ \\ ${ }^{1}$ Department of Speech and Language, Escola Paulista de Medicina at \\ Universidade Federal de São Paulo, São Paulo, SP, Brazil \\ Int Arch Otorhinolaryngol 2014;18:239-243.
}

\begin{abstract}
Address for correspondence Zelita Caldeira Ferreira Guedes, PhD, Department of Speech and Language, Escola Paulista de Medicina at Universidade Federal de São Paulo, Rua Bandeira Paulista 147/14Itaim Bibi, CEP: 04532-010 São Paulo, SP-Brazil (e-mail: zelitaferreira@uol.com.br).
\end{abstract}

\begin{abstract}
Keywords

- misoprostol

- speech disorders

- rehabilitation of speech and language disorders

Introduction Möbius syndrome (MS; VI and VII palsy) is a rare disease that in Brazil has a great frequency because of the use of misoprostol during pregnancy.

Objective Verify if the speech and language performance of children with MS whose mothers reported use of misoprostol (Cytotec, Pfizer, Connecticut, USA) are different from the performance of children of mothers who did not report use.

Methods The stomatognathic system beyond receptive and expressive language and speech was evaluated in children with MS, and their mothers were questioned whether they used misoprostol during the pregnancy.

Results During the interview, $61.11 \%$ of mothers reported that they took misoprostol during the pregnancy. Most of the subjects (83.3\%) whose mothers took misoprostol presented bilateral palsy beyond bad mobility of the tongue $(90.9 \%)$ and speech disorders (63.6\%).

Conclusion The number of mothers who took misoprostol without knowing the risk for MS was great. The lack of facial expressions and speech disorders were common characteristics of the individuals with MS, whether the mothers took misoprostol during the pregnancy or not.
\end{abstract}

\section{Introduction}

Möbius syndrome (MS) was described in 1888. It is characterized by the feeling of wearing a face mask, and it involves the sixth and seventh cranial nerves. Necropsies showed some causes for this problem: hypoplasia or absence of central brain nuclei, destructive degeneration of central brain nuclei, peripheral nerve involvement, and myopathy. This disease may be associated with other cranial and musculoskeletal anomalies. ${ }^{1-3}$

Studies document that a paresis or paralysis of the seventh cranial nerve can be accompanied by paralysis of many other pairs of nerves. Because of changes to organs that form between 23 and 46 days of embryonic life, a common factor might affect all these structures. The most accepted hypothesis is that of a disruption of the vascular system or other mechanisms such as hemorrhage, thrombosis, or stenosis involving veins of the second pharyngeal arch, facial arteries, and the absence of triplet formation of the vertebral basilar system affect the development of the core cranial nerves.

The disease occurs sporadically, but it can occur in the same family. ${ }^{4}$ The genetics may be autosomal dominant or autosomal recessive, and X-linked recessive cytogenetic studies show its location on chromosome 13, loci on 3q21-q22 and 10q21.3-q22.1. Causes cited are also teratogenic, ${ }^{5-8}$ and these are apparently the most common in Brazil. Misoprostol (synthetic analog of natural prostaglandin E1; Cytotec, Pfizer, Connecticut, USA) has been used orally and vaginally in the first months of pregnancy in an attempt to interrupt it. Studies suggest that there is a strong association between attempted abortion with misoprostol and the subsequent birth of individuals with MS. Misoprostol can also be used received

January 13, 2013

accepted

August 23, 2013

published online

March 21, 2014
DOI http://dx.doi.org/

10.1055/s-0033-1363466. ISSN 1809-9777.
Copyright (c) 2014 by Thieme Publicações License terms Ltda, Rio de Janeiro, Brazil 
to decrease the blood flow in gastric ulcers, which in our population corresponded to 11 mothers (61.1\%).

Both the location of anomalies and their severity vary from patient to patient, and a systematic study needs to be performed to recognize more clearly the pathogenesis of the disease. ${ }^{9,10}$ We have found individuals with cleft palate and micrognathia-associated congenital clubfeet and changes in IX, X, XI and XII cranial nerves, similar to the authors mentioned previously. Such anomalies disrupt stomatognathic functions of sucking, chewing, swallowing, and speech and can slow the patient's motor development.

According to some researchers, ${ }^{7}$ the pathophysiology of this disease begins in infancy, but its manifestations occur until the birth stage. Because both soft tissues and bone can be affected, these individuals require multidisciplinary treatment throughout development to adulthood.

The child with MS has difficulty sucking and swallowing at birth and requires speech therapy for specific training. Often associated with this difficulty is mandibular hypoplasia and retrognathia, ${ }^{11}$ which can change the shape and mobility of the tongue. When oral feeding is considered impossible, gastrostomy should be indicated.

Another manifestation present at birth is the inability to close the mouth, which favors drooling, as the deficit prevents the ejection of saliva into the pharynx.

Lack of facial expression (crying, laughing) hinders communication with the child's mother in the first few months, and she is not able to identify if the sounds made by the baby are related to pain or pleasure.

Eye occlusion is also altered, ${ }^{8}$ requiring eye care to prevent drying of the cornea, as the child is also unable to blink. Convergent strabismus is also present and requires corrective surgery in a timely manner.

When the cranial nerves (IX, X, XII, and XII) are also affected, ${ }^{10}$ children have difficulty swallowing, and they lack of velopharyngeal sphincter closing and laryngeal incoordination. Speech will also be affected, ${ }^{12,13}$ requiring speech therapy to produce phonemes, which often requires compensatory procedures.

The clubfoot should be evaluated by an orthopedist, ${ }^{6}$ who will decide on surgical need. The delay in this correction will interfere with the patient's motor development. Other anomalies may occur in the upper extremities, such as polydactyly, syndactyly, and artrogriposis. These should also be evaluated, and the appropriate course of action should be performed in the shortest possible time so as not to jeopardize the development of this child.

The congenital facial palsy usually originates in the embryonic stage, and it is not known how to make these nerves become normal. ${ }^{2}$ Thus, the surgical resources should only be offered to the patient when he/she is a teenager, as the surgery will not change the face to the normal aspect, neither adequate the functions.

As previously mentioned, in Brazil, the use of misoprostol was the most common cause of MS. In our institution since 1989, a large number of mothers reported on their use of the drug. We investigated whether there were differences in the manifestations of these individuals with MS, depending on the etiology of the disease: teratogenic or otherwise. Therefore, we describe the conditions of individuals with MS treated at our institution whose mothers and/or caregivers reported on the use of misoprostol during pregnancy to see if the disease manifested differently.

\section{Methods}

A total of 18 females and males, aged from 4 months to 10 years, with a previous diagnosis of MS between August 2008 and December 2009 came to our hospital. They were from different areas and received evaluation and/or counseling. Many were referred by health professionals or through the Web site that addresses the topic, available on the homepage of this institution. The inclusion criterion for our study was the previous diagnosis of MS. The exclusion criterion was different diseases from MS.

Mothers and/or guardians of these individuals gave case histories, and the patients reviewed the stomatognathic system and understanding and expression of language contained in the protocol used in this sector. ${ }^{14}$ Data were recorded for statistical analysis.

The assessment and interview protocols followed for the exclusive care of patients born with MS used in the institution have been published, ${ }^{14}$ and they cover information on speech, language, voice, and stomatognathic system (structures and functions), including questions about identification, history, pregnancy, delivery, and development of the individual, as well as information regarding the use of abortive or other drugs. ${ }^{15}$

In our institution, data concerning the individuals recorded in medical records can be used for research purposes, provided that the patient's identity is kept confidential and that consent is given prior to application of the procedures (CEP 1038/10 Ethics and Research Commission from the Institution).

- Table 1 shows the individuals' sex and age.

All data taken from the records and the different manifestations were analyzed independently or in relation to each other, according to the hypotheses of whether mothers who had taken misoprostol could cause worsened disease.

We used testing equality of two ratios, chi-square for independence, and confidence intervals for the mean; a $p$ value of 0.05 (5\%) was considered significant.

\section{Results}

The subjects came from different localities and institutions seeking guidance or evaluation and clinical care. Some were from other cities or already receiving some form of speech

Table 1 Gender distribution for the overall sample

\begin{tabular}{|l|l|l|l|}
\hline Gender & $\boldsymbol{n}$ & $\%$ & $\boldsymbol{p}$ value \\
\cline { 1 - 3 } Female & 7 & 38.9 & 0.182 \\
\cline { 1 - 3 } Male & 11 & 61.1 & \\
\hline
\end{tabular}


therapy. Those from other cities often requested continuation of therapy procedures at home. Some professionals (speech therapists, physiotherapists, nurses) accompanied the visiting families. The demographic profiling of this population was not a focus of this research. ${ }^{15}$

Of the mothers, $61.1 \%$ admitted taking the drug Cytotec at some time during pregnancy, usually in the first few weeks; others denied use or were evasive. Such data were not statistically significant. Only one grandmother said that during pregnancy her daughter used "hard drugs" (concomitant use of teratogenic drugs).

Specific evidence described by participants most commonly referred to facial movements. We found that most had paralysis on both sides of the face. As for the other events mentioned in the literature, such as changes in the hands, feet, cleft palate, and strabismus requiring surgical correction, the results were as follows: no subject had abnormal hands; some individuals had clubfoot but had reconstructive surgery; others had convergent strabismus and also had specific treatment (surgery and/or use of buffer); and others had palatoplasty. Some mothers reported complications during pregnancy such as hypertension and diabetes, and some patients were born prematurely.

Most subjects showed no otorhinolaryngologic changes. Few central nervous system changes were manifested, such as seizure disorders and vascular calcification. Although the most common manifestation related to food and speech, some mothers complained that their children presented little understanding of speech.

Almost half of the individuals had not yet established speech or speech was delayed for their age. Many showed enough tongue mobility for swallowing and speech. Few showed changes compatible with the disease, as the realization of bilabial consonants articulation at other places but the lips and difficulty achieving the apical tongue sounds (paralysis of the orbicular muscles of the mouth and tongue paresis).

Most individuals regularly attended classes in basic schools and a few were too young to attend or their parents did not think it was convenient to put them in daycare centers or preschools (-Table 2).

Data from these subjects were evaluated separately to study the hypothesis that misoprostol taken during

Table 2 Distribution of data for overall sample

\begin{tabular}{|l|l|l|l|l|l|}
\hline \multirow{2}{*}{ Overall } & \multicolumn{2}{|c|}{ No } & \multicolumn{2}{c|}{ Yes } & \multirow{2}{*}{ value } \\
\cline { 2 - 6 } & $n$ & $\%$ & $n$ & $\%$ & \\
\hline Amb & 15 & 83.3 & 3 & 16.7 & $<0.001^{\mathrm{a}}$ \\
\hline ADL & 7 & 38.9 & 11 & 61.1 & 0.182 \\
\hline Hand Sur & 18 & 100.0 & 0 & 0 & $<0.001^{\mathrm{a}}$ \\
\hline Eye Sur & 15 & 83.3 & 3 & 16.7 & $<0.001^{\mathrm{a}}$ \\
\hline Palate Sur & 14 & 77.8 & 4 & 22.2 & $<0.001^{\mathrm{a}}$ \\
\hline Foot Sur & 13 & 72.2 & 5 & 27.8 & $0.008^{\mathrm{a}}$ \\
\hline Misoprostol & 7 & 38.9 & 11 & 61.1 & 0.182 \\
\hline Under & 12 & 66.7 & 6 & 33.3 & $0.046^{\mathrm{a}}$ \\
\hline Drugs & 17 & 94.4 & 1 & 5.6 & $<0.001^{\mathrm{a}}$ \\
\hline Emiss & 7 & 38.9 & 11 & 61.1 & 0.182 \\
\hline School & 12 & 66.7 & 6 & 33.3 & $0.046^{\mathrm{a}}$ \\
\hline Squint & 0 & 0 & 18 & 100.0 & $<0.001^{\mathrm{a}}$ \\
\hline Speech & 8 & 44.4 & 10 & 55.6 & 0.505 \\
\hline Sp Ther & 13 & 72.2 & 5 & 27.8 & $0.008^{\mathrm{a}}$ \\
\hline Gest & 15 & 83.3 & 3 & 16.7 & $<0.001^{\mathrm{a}}$ \\
\hline Comm & 7 & 38.9 & 11 & 61.1 & 0.182 \\
\hline Upper Limb & 15 & 83.3 & 3 & 16.7 & $<0.001^{\mathrm{a}}$ \\
\hline Tongue Mob & 5 & 27.8 & 13 & 72.2 & $0.008^{\mathrm{a}}$ \\
\hline Eye Mob & 6 & 33.3 & 12 & 66.7 & $0.046^{\mathrm{a}}$ \\
\hline Neuro & 15 & 83.3 & 3 & 16.7 & $<0.001^{\mathrm{a}}$ \\
\hline ORL & 17 & 94.4 & 1 & 5.6 & $<0.001^{\mathrm{a}}$ \\
\hline
\end{tabular}

Abbreviations: ${ }^{a}$ statiscally significant; Amb, residence at the clinic; ADL, perform activities of daily living independently; Hand Sur, syndactyly surgery; Eye Sur, eye surgery for strabismus; Palate Sur, palatoplasty; Misoprostol, use of misoprostol during pregnancy mentioned by the mother or guardian; Under, speech understanding; Drugs, illicit drug use during pregnancy mentioned by the mother or guardian; Emiss, presence of emission-speech issue; School, schooling; Squint, squint present; Speech, speech quality; Sp Ther, service of speech therapy; Gest, presence of mimic; Comm, presence of communication; Upper Limb, malformation in upper limb; Tongue Mob, presence of tongue mobility; Eye Mob, presence of eye's mobility; Neuro, proven presence of neurologic changes; ORL, proven presence of otorhinolaryngology changes. 
pregnancy could present more severe neurologic manifestations or a greater number of associated complications and are shown in - Table 3. Neurologic changes were not evident in these individuals (-Table 4). There were also no differences for the speech and language difficulties.

\section{Discussion}

We correlated the data compiled for this population and data found in the literature to study whether ingestion of misoprostol during pregnancy caused more severe disease or manifestations different from that in subjects whose mothers reported no intake.

Individuals whose mothers reported that they had taken misoprostol (61.1\%) did not show different manifestations that those whose mothers did not report drug intake. Although data that misoprostol can cause MS exist in the literature,,$^{5-7}$ these refer to the usual manifestations of the disease, such as strabismus and congenital clubfeet, ${ }^{7,8}$ and no differences in language disorders and central nervous system were reported, as was found in our study.

Our patients came from other places and institutions. Three $(16.7 \%)$ of these individuals came to our outpatient clinic after consultation and assessment interview. Although some references discussed different professionals' work with these individuals, ${ }^{16}$ none of the other articles mentioned long-term therapeutic monitoring. ${ }^{8}$ The references report results from research conducted with these individuals, with no record of visits to specific clinics such as ours for this type of patient.

The use of misoprostol in our sample was presented as a possible cause of MS in these individuals. ${ }^{5-7}$ In France, ${ }^{7}$ a survey demonstrated that ingestion of misoprostol abortion and other drugs during the seventh week of pregnancy can cause the onset of MS in the baby. These authors warn that the critical period is between the fifth and eighth weeks of gestation and therefore mothers should be advised about the risk of ingestion of this drug. Unfortunately in our country, even if they are warned, many women prefer to take the risk, with the hope that the abortion is performed. We found no evidence in the references of other events in mothers during pregnancy, such as hypertension and diabetes, as were found in our study.

The disease is characterized by lack of facial expression (VII cranial nerve paralysis) and eye shift mobility (cranial nerve VI). ${ }^{1-3,8}$ Bilateral facial palsy occurred in $83.3 \%$ of individuals in this sample. Although this event may also be unilateral the most frequently found is bilateral. According to our observation in individuals who were already treated in our clinic, the fact that the demonstration was bilateral does not exclude the fact that one side may be better than the other.

The most common manifestation accompanying facial paralysis and lack of mobility of the eyes to the sides is the occurrence of congenital clubfeet. ${ }^{6,8}$ Some cases also have cleft palate. ${ }^{11}$ These manifestations have been described in the literature, and the individuals evaluated in our outpatient clinic corroborate these findings.

The most common complaint among mothers, after the absence of facial movements, referred to feeding and speech $^{2,12,13}$; however, problems as understanding language $^{16}$ and changes in neurologic examinations, such as calcifications and vascular changes, ${ }^{10,17}$ were also discussed. The occurrence on the difficulty of understanding language ${ }^{16}$ does not seem to be frequent; however, in our sample we found $33.3 \%$ of mothers who complained about this in their children. Among the data, we found that 3 subjects (16.7\%) manifested seizures changes, disorders, and vascular calcifications $(p<0.001)$. Some authors cite disorders and vascular calcifications as manifestations accompanying this paralysis. $^{10,18}$

Approximately $44.4 \%$ of our subjects had not yet begun talking, due to early age and a slight delay in language development. Thirteen individuals (72.2\%) had sufficient tongue mobility for swallowing and speech. Only 5 (27.8\%) showed the expected changes of the disease, such the realization of bilabial consonants articulation at other places that not lips and difficulty achieving the apical tongue sounds, as mentioned by other authors. ${ }^{12,13}$

Most patients had been attending school regularly, ${ }^{17}$ and the youngest has not attended because it was not convenient for the parents.

We raised the hypothesis that the use of misoprostol could aggravate the common manifestations of this disease, but our isolated analysis of the results of individuals whose mothers took Cytotec demonstrated no significant differences. Some authors did not follow the development of individuals whose mothers ingested the drug and therefore cannot check if those subjects had more severe manifestations than individuals whose mothers did not use the drug. ${ }^{5-8}$

Table 3 Relationship between altered CNS and using misoprostol during pregnancy $(p=0.914)$

\begin{tabular}{|c|c|c|c|c|c|c|}
\hline \multirow[t]{3}{*}{ CNS } & \multicolumn{4}{|c|}{ Misoprostol } & \multirow{2}{*}{\multicolumn{2}{|c|}{ Total }} \\
\hline & \multicolumn{2}{|c|}{ No } & \multicolumn{2}{|c|}{ Yes } & & \\
\hline & $n$ & $\%$ & $n$ & $\%$ & $n$ & $\%$ \\
\hline No & 4 & 57.1 & 6 & 54.5 & 10 & 55.6 \\
\hline Yes & 3 & 42.9 & 5 & 45.5 & 8 & 44.4 \\
\hline Total & 7 & 38.9 & 11 & 61.1 & 18 & 100 \\
\hline
\end{tabular}

Abbreviation: CNS, central nervous system. 
Table 4 Relationship between language disorder and use of misoprostol during pregnancy $(p=0.205)$

\begin{tabular}{|c|c|c|c|c|c|c|}
\hline \multirow[t]{3}{*}{ Language } & \multicolumn{4}{|c|}{ Misoprostol } & \multirow{2}{*}{\multicolumn{2}{|c|}{ Total }} \\
\hline & \multicolumn{2}{|c|}{ No } & \multicolumn{2}{|c|}{ Yes } & & \\
\hline & $n$ & $\%$ & $n$ & $\%$ & $n$ & $\%$ \\
\hline No & 4 & 57.1 & 3 & 27.3 & 7 & 38.9 \\
\hline Yes & 3 & 42.9 & 8 & 72.7 & 11 & 61.1 \\
\hline Total & 7 & 38.9 & 11 & 61.1 & 18 & 100 \\
\hline
\end{tabular}

Since 1989 our services have been offered to individuals with MS, including myofunctional stimulation, which after some time presents some results (especially if the patient has one side less affected than the other) and also encourages the use of gestures, which serve as addition to communication. However, the frequency of visits has grown in recent years and individuals are coming earlier (4 months), suggesting that the diagnosis is made earlier and referrals made more objectively.

\section{Conclusions}

Individuals whose mothers took misoprostol during pregnancy showed manifestations similar to those of individuals whose mothers did not report drug intake, in agreement with the data found in the literature. There was a large contingent of women who took misoprostol without knowing its teratogenic action.

\section{References}

1 Allen BM, Wert MA, Tatum SA. Congenital unilateral multiple cranial neuropathy: an etiology shared with Mobius syndrome? Int J Pediatr Otorhinolaryngol 2006;70(5):931-934

2 Fons-Estupiñá MC, Póo P, Colomer J, Campistol J. Secuencia de Moebius: hallazgos clinicorradiológicos. Rev Neurol 2007;44(10): 583-588

3 Slimani F, Hamzy R, Allali B, Zaghloul K, Benjelloun A, ChekkouryIdrissi A. Möbius syndrome. Rev Stomatol Chir Maxillofac 2010; 11(5-6):299-301

4 Dumars S, Andrews C, Chan WM, Engle EC, Demer JL. Magnetic resonance imaging of the endophenotype of a novel familial Möbius-like syndrome. J AAPOS 2008;12(4):381-389

5 Pastuszak AL, Schüler L, Speck-Martins CE, et al. Use of misoprostol during pregnancy and Möbius' syndrome in infants. N Engl J Med 1998;338(26):1881-1885
6 Almeida MBV, Brandt CT, Lima JA, et al. A incidência de anomalias ortopédicas em portadores da seqüência de Möbius e sua associação com o uso do misoprostol. Rev Bras Ortop 2007;42(1/2): 10-16

7 Bos-Thompson MA, Hillaire-Buys D, Roux C, Faillie JL, Amram D. Möbius syndrome in a neonate after mifepristone and misoprostol elective abortion failure. Ann Pharmacother 2008;42(6):888-892

8 Miller MT, Ventura L, Strömland K. Thalidomide and misoprostol: Ophthalmologic manifestations and associations both expected and unexpected. Birth Defects Res A Clin Mol Teratol 2009;85(8): 667-676

9 Abramson DL, Cohen MM Jr, Mulliken JB. Möbius syndrome: classification and grading system. Plast Reconstr Surg 1998; 102(4):961-967

10 Huang HT, Hwang CW, Lai PH, Chen CC. Möbius syndrome as a syndrome of rhombencephalic maldevelopment: a case report. Pediatr Neonatol 2009;50(1):36-38

11 Roig Quilis M. Brainstem dysgenesis: Möbius, Cogan and Pierre Robin syndromes revisited. An Pediatr (Barc) 2005;62(4):346-351

12 Terzis JK, Karypidis D. Direct tongue neurotization: the effect on speech intelligibility in patients with Möbius syndrome. Plast Reconstr Surg 2010;125(1):150-160

13 Von Berg S, McColl D, Brancamp T. Moebius syndrome: measures of observer intelligibility with versus without visual cues in bilateral facial paralysis. Cleft Palate Craniofac J 2007;44(5): 518-522

14 Albuquerque TCAL, Barreto RRS, Costa TCCM, Guedes ZCF. Sequência de Möbius: protocolo de anamnese e avaliação-relato de caso. Rev. Soc Bras Fonol 2009;14(1):115-122

15 Sena M, Ventura L, Miller M, de Almeida HC, Leal DB, Brandt CT. Perfil sócio demográfico e gestacional de indivíduos com a seqüência de Möbius An.. Fac Med Univ Fed Pernamb 2003;48(1):36-41

16 Limongi SCO, Boari C, Silva DRA, Brigagão GM, Moraes LMS, Toledo $\mathrm{L}$, et al. Intervenção fonoaudiológica precoce na Seqüência de Möebius: relato de caso. Pro Fono 1996;8(2):55-61

17 Briegel W, Schimek M, Knapp D, Holderbach R, Wenzel P, Knapp EM. Cognitive evaluation in children and adolescents with Möbius sequence. Child Care Health Dev 2009;35(5):650-655

18 Dooley JM, Stewart WA, Hayden JD, Therrien A. Brainstem calcification in Möbius syndrome. Pediatr Neurol 2004;30(1):39-41 